\title{
The Role of Renal Replacement Therapy in the Management of Pharmacologic Poisonings
}

\author{
Aibek E. Mirrakhimov, ${ }^{1}$ Aram Barbaryan, ${ }^{2}$ Adam Gray, ${ }^{1}$ and Taha Ayach $^{3}$ \\ ${ }^{1}$ Department of Medicine, University of Kentucky College of Medicine, Lexington, KY, USA \\ ${ }^{2}$ Department of Internal Medicine, University of Kansas Medical Center, Kansas City, KS, USA \\ ${ }^{3}$ Division of Nephrology, Bone and Mineral Metabolism, University of Kentucky College of Medicine, Lexington, KY, USA
}

Correspondence should be addressed to Aibek E. Mirrakhimov; amirrakhimovl@gmail.com

Received 6 September 2016; Revised 13 October 2016; Accepted 24 October 2016

Academic Editor: Alessandro Amore

Copyright (C) 2016 Aibek E. Mirrakhimov et al. This is an open access article distributed under the Creative Commons Attribution License, which permits unrestricted use, distribution, and reproduction in any medium, provided the original work is properly cited.

\begin{abstract}
Pharmacologic toxicities are common and range from mild to life-threatening. The aim of this study is to review and update the data on the role of renal replacement therapy (RRT) in the management of various pharmacologic poisonings. We aim to provide a focused review on the role of RRT in the management of pharmacological toxicities. Relevant publications were searched in MEDLINE with the following search terms alone or in combination: pharmacologic toxicity, hemodialysis, hemofiltration, renal replacement therapy, toxicology, poisonings, critical illness, and intensive care. The studies showed that a pharmacologic substance should meet several prerequisites to be deemed dialyzable. These variables include having a low molecular weight $(<500 \mathrm{Da})$ and low degree of protein binding $(<80 \%)$, being water-soluble, and having a low volume of distribution $(<1 \mathrm{~L} / \mathrm{kg})$. RRT should be strongly considered in critically ill patients presenting with toxic alcohol ingestion, salicylate overdose, severe valproic acid toxicity, metformin overdose, and lithium poisoning. The role of RRT in other pharmacologic toxicities is less certain and should be considered on a case-by-case basis.
\end{abstract}

\section{Introduction}

Pharmacological substances carry an intrinsic risk of toxicity as the result of either idiosyncrasy or overdose. For example, there were 2,188,013 cases of human exposures to various toxic substances resulting in 20,749 cases of serious adverse reactions and 1,552 deaths in 2013 [1]. In such cases, hemodialysis was used in more than 2,290 cases [2]. In the year 2014, pharmaceutical toxicities were responsible for $61.4 \%$ of cases and nonpharmacological exposures accounted for $14.1 \%$ of registered cases in 2014 [2].

The goal of this article is to review the data and evidence on the use of RRT in the management of certain pharmacologic overdoses. First, we review and discuss the different factors that would affect dialyzability of drugs and toxins. Second, we discuss different extracorporeal treatment modalities with focus on hemodialysis and hemofiltration treatments.
Third, we review the role of RRT in the management of specific drugs and poisons including toxic alcohols, salicylate, lithium, metformin, valproic acid, and dabigatran. Lastly, we discuss the role of RRT in the management of less common miscellaneous cases of intoxication.

It is important to mention that the management of the toxicities mentioned above is complex and usually requires measures in addition to dialysis.

\section{Removal of Drugs and Toxins by Extracorporeal Therapies}

The use of extracorporeal techniques to remove toxins is justified if there is an indication of severe toxicity. The extent to which a drug is affected by extracorporeal therapies is determined primarily by several physicochemical 
TABLE 1: Optimal physicochemical properties for extracorporeal removal of drugs.

\begin{tabular}{|c|c|c|c|}
\hline & Hemodialysis & Hemofiltration & Hemoperfusion \\
\hline $\begin{array}{l}\text { Molecular } \\
\text { weight }\end{array}$ & $<500 \mathrm{Da}$ & $<40 \mathrm{KDa}$ & $<40 \mathrm{KDa}$ \\
\hline Protein binding & Low $(<80 \%)$ & Low & Low or high \\
\hline $\begin{array}{l}\text { Volume of } \\
\text { distribution }\end{array}$ & $<1 \mathrm{~L} / \mathrm{Kg}$ & $<1 \mathrm{~L} / \mathrm{Kg}$ & $<1 \mathrm{~L} / \mathrm{Kg}$ \\
\hline Solubility & Water & Water & Water or lipid \\
\hline $\begin{array}{l}\text { Endogenous } \\
\text { clearance }\end{array}$ & $<4 \mathrm{~mL} / \mathrm{Kg} / \mathrm{min}$ & $<4 \mathrm{~mL} / \mathrm{Kg} / \mathrm{min}$ & $<4 \mathrm{~mL} / \mathrm{Kg} / \mathrm{min}$ \\
\hline
\end{tabular}

characteristics of the drug which are summarized in Table 1. These include molecular size, protein binding, volume of distribution, water solubility, and endogenous clearance. In addition to these properties of the drug, technical aspects of the procedure may also determine the extent to which a drug is removed $[3,4]$.

2.1. Molecular Weight. Dialysis is dependent upon the use of a synthetic dialytic membrane with fixed pore size. The movement of drugs or other solutes is largely determined by the size of these molecules in relation to the pore size of the membrane. As a general rule, smaller molecular weight substances will pass through the membrane more easily than larger molecular weight substances.

2.2. Protein Binding. Another important factor determining drug removal during dialysis is the concentration gradient of unbound (free) drug across the dialysis membrane. Because the primary binding proteins for most drugs (mainly albumin) are of large molecular size, the drug protein complex is often unable to cross the dialysis membrane. Drugs with a high degree of protein binding will have a low plasma concentration of unbound drug available for dialysis and therefore lower clearance.

2.3. Volume of Distribution. The efficacy of toxin removal is also influenced by its theoretical volume of distribution (VD). A drug with a large VD is distributed widely throughout tissues and is present in relatively small amounts in the blood. Factors that contribute to a large VD include a high degree of lipid solubility and low plasma protein binding. Drugs with a large volume of distribution $(>1 \mathrm{~L} / \mathrm{kg})$ are likely to be minimally dialyzed.

2.4. Water Solubility. The dialyzate used for hemodialysis is an aqueous solution. In general, drugs with high water solubility will be dialyzed to a greater extent than those with high lipid solubility. Highly lipid-soluble drugs tend to be distributed throughout tissues, and therefore only a small fraction of the drug is present in plasma and is accessible for dialysis.

2.5. Endogenous Clearance. This includes renal and nonrenal (mainly hepatic) clearance of the drug. Dialysis will have a limited impact if the rate of drug removal is significantly faster by endogenous routes ( $>4 \mathrm{~mL} / \mathrm{Kg} / \mathrm{min})$. It is generally accepted that use of extracorporeal treatment is justified, if at least $30 \%$ can be added to total body clearance by such treatment.

\section{Extracorporeal Treatment Modalities}

The extracorporeal techniques most frequently employed for the removal of toxins are intermittent hemodialysis, continuous renal replacement therapy, and hemoperfusion. There are a few reports on the use of molecular adsorbent recirculating system (MARS) in poisoning, specifically for those toxins that are strongly protein bound; however, the use of MARS is limited by its availability, technical applicability, and high costs.

3.1. Intermittent Hemodialysis. During hemodialysis (HD), toxins and other solutes are cleared from the blood by diffusion against a steep concentration gradient through a semipermeable membrane into dialyzate. In addition to its specific properties (Table 1), the clearance of a toxic substance during HD depends also on membrane surface area and type, as well as on blood and dialyzate flow rates. HD comes in standard as well as high-efficiency or highflux modalities. The major difference is the pore size of the membrane, the type of membrane, and the amount of dialyzate flow that occurs. Increasing blood and dialyzate flow rates can increase the concentration gradient between blood and dialyzate, thus optimizing the rates of diffusion and elimination. Clearances can also be enhanced by increasing dialyzer efficiency or membrane surface area. Larger-solute removal can be enhanced by increasing dialyzer flux when intermittent HD is used (for toxins $>500 \mathrm{~d}$ and up to $10,000 \mathrm{~d}$ ) or by switching to hemofiltration, which is usually applied continuously as discussed later.

The major drawback of HD is the risk of rebound toxicity after cessation of the treatment, due to redistribution of the toxin between body compartments. Extending the HD session beyond 4 hours can to some extent ameliorate rebound; however, this may not be easily feasible. An alternative or adjunctive solution is to increase dialysis session frequency or switch to continuous therapy after initial HD treatment specifically for substances with higher volume of distribution.

Intermittent $\mathrm{HD}$ is usually the first-choice extracorporeal modality because of its common availability, the rapidity of toxin removal, and the low molecular weight of the common agents of poisoning [5].

3.2. Continuous Renal Replacement Therapy (CRRT). The use of CRRT has become common practice in Intensive Care Unit (ICU) settings during the last 2 decades for treatment of acute kidney injury. The term CRRT is commonly used to describe all continuous modalities of hemofiltration. Continuous venovenous hemofiltration (CVVH) is the most commonly used of the CRRT modalities, where dialysis occurs by convective transport. In continuous venovenous hemodiafiltration (CVVHDF), diffusive transport of molecules is combined 
with convective removal in order to mainly improve the clearance of small solutes [6].

The main advantage of CRRT is its applicability in hemodynamically unstable patients. It can be easily set up and run by regular ICU staff, thereby avoiding the need for specially trained dialysis nurses and technicians. The membranes used in CRRT are typically more permeable compared to standard intermittent HD membranes. Most high-flux HD membranes allow for the clearance of molecules up to $10,000 \mathrm{Da}$. CRRT membranes allow for the clearance of molecules as large as $20,000-40,000 \mathrm{Da}$ and therefore would be the preferred modality for larger toxins removal. Another advantage of CRRT is the ability to avoid rebound of toxins removed from intravascular space, due to continuous nature of the procedure and slower rate of clearance, leading to less dramatic decreases in plasma drug levels and slower reequilibration of toxins between intracellular and intravascular spaces $[5,7]$.

Although CRRT gives better longer-term solute clearances (over the course of several days), it is less efficient in the short term and does not provide the rapidity of elimination afforded by intermittent HD when minimizing toxin exposure is a high priority. Other disadvantages of CRRT include the requirement for intensive anticoagulation which can place a patient at risk for bleeding and it is more associated with electrolyte disturbances. Finally, CRRT is not available at many smaller hospitals, possibly due to high equipment, training, and staffing costs $[4,8]$.

There are abundant case reports as well as a few small case series in the medical literature documenting the use of CRRT in the treatment of poisonings, but specific techniques and the clinical outcomes vary considerably. Therefore, one cannot draw definitive conclusions regarding benefit. Some patients, particularly those who are hemodynamically unstable and are not candidates for conventional HD, may warrant a trial of CRRT. If it is logistically possible, an ideal combination may be initial use of intermittent $\mathrm{HD}$ for rapid reduction of toxin levels followed by continuous therapy to ameliorate any postdialysis rebound when this is predicted. Controlled trials to better clarify the role of CRRT in treatment of poisonings would be beneficial, though such studies would be extremely difficult to conduct in this field [8].

3.3. Hemoperfusion. Hemoperfusion consists of the passage of anticoagulated blood through a cartridge containing an adsorbent material such as activated charcoal or a resin. In order to be removed by hemoperfusion, the toxic substance must have binding affinity to the sorbent in the cartridge and a low volume of distribution (Table 1). Water-soluble and lipid-soluble substances with molecular weights ranging from 100 to 40,000 daltons are well adsorbed with hemoperfusion.

In general, hemoperfusion is preferred to hemodialysis for the removal of chemicals that are lipid-soluble or are highly protein bound. However, the advantage of hemoperfusion over HD has lessened with the advent of high-flux dialysis membranes. Additionally, there is generally greater expertise and availability with respect to hemodialysis than hemoperfusion [42].

\section{Renal Replacement Therapy in the Management of Specific Pharmacologic Poisonings}

4.1. Toxic Alcohol Ingestion. Methanol, ethylene glycol, diethylene glycol, and isopropyl alcohol (also known as isopropanol) are alcohols commonly used in household solutions such as various cleaners, disinfectants, solvents, and antifreeze solutions as well as machine fluids [43-45]. There were 52,430 exposures to alcohols resulting in 174 fatalities in 2013 [46]. The vast majority of methanol, ethylene glycol, and isopropyl alcohol toxicities arise either as a result of suicidal attempts or after drinking the toxic alcohol as a substitute for ethanol [43]. However, the vast majority of diethylene glycol toxicities are the result of the introduction of diethylene glycol into various pharmacologic substances as a substitution for more expensive and less toxic substances [45].

To understand the basic pathogenesis of methanol, ethylene glycol, diethylene glycol, and isopropyl alcohol toxicities, it is important to briefly review the metabolism in vivo. When ingested, both methanol and ethylene glycol undergo an initial biochemical reaction catalyzed by alcohol dehydrogenase (the same enzyme metabolizing ethanol), which converts the parent alcohol into formaldehyde and glycolaldehyde, respectively. The final products of methanol and ethylene glycol metabolism are formic acid and oxalic acid, respectively [43]. The metabolism of methanol and ethylene glycol disrupts cellular energy metabolism leading to cellular damage $[47,48]$. These end products result in classic features of toxicity such as retinal toxicity caused by methanol and renal injury mediated by oxalic acid.

The first step of diethylene glycol metabolism also involves the alcohol dehydrogenase enzyme which converts diethylene glycol into 2-hydroxyethoxyacetaldehyde [45]. Aldehyde dehydrogenase enzyme, in turn, converts 2-hydroxyethoxyacetaldehyde into 2-hydroxyethoxyacetic acid. The pathogenesis of diethylene glycol toxicity was first believed to involve the in vivo formation of ethylene glycol as the result of metabolism. However, further animal studies showed that the major toxic metabolite is 2hydroxyethoxyacetic acid and that the metabolic conversion of diethylene glycol into ethylene glycol does not occur in vivo [45].

The first step of isopropyl alcohol in vivo metabolism also involves the enzyme alcohol dehydrogenase, which converts it into acetone. Acetone, in turn, undergoes several intermediate metabolic steps with the end product being glucose [44]. It is important to note that, in the vast majority of cases, isopropyl alcohol appears to be less toxic than methanol and ethylene glycol which are associated with greater toxicities and mortality rates [44, 47, 48].

The clinical presentations of methanol, ethylene glycol, and isopropyl alcohol overlap and include CNS depression, altered mental status, and seizures. Retinal toxicity and blindness are more specific for methanol intoxication, and acute kidney injury and hypocalcemia are more typical for ethylene glycol intoxication. Laboratory testing and diagnosis of methanol and ethylene glycol are based on the presence of 


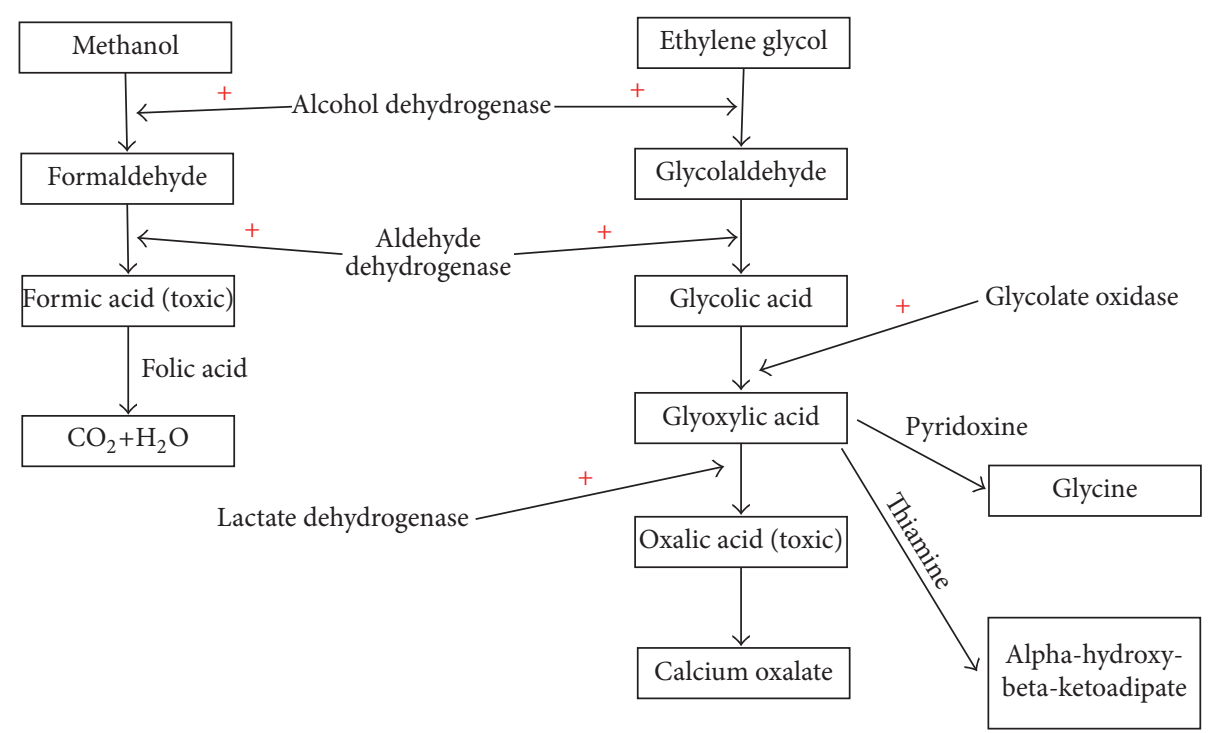

Figure 1: An overview of in vivo methanol and ethylene glycol metabolism.

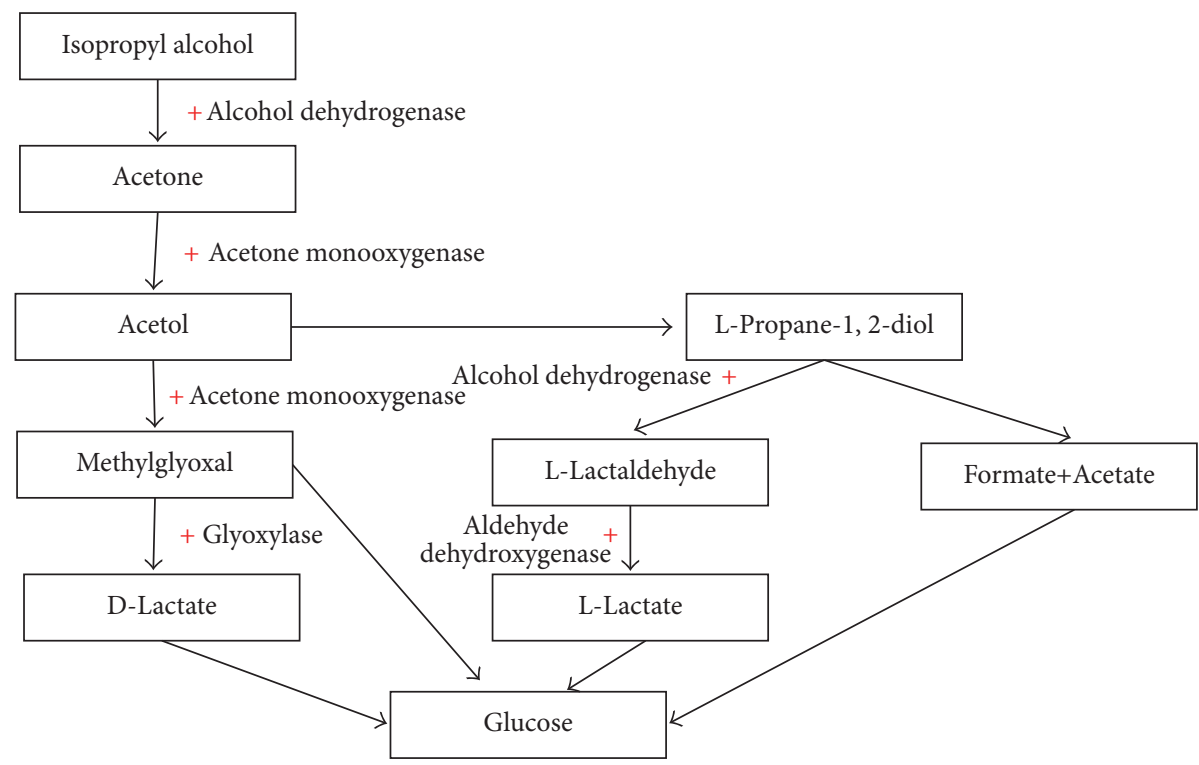

Figure 2: An overview of in vivo isopropyl alcohol metabolism.

a high anion gap metabolic acidosis, presence of a serum osmolal gap (a difference between measured osmolality and calculated osmolality $\geq 10$ ), and measuring the levels of the toxic alcohols which is used for confirmation (typically these tests are not time sensitive, and treatment should not be withheld in any patient suspected of having toxic alcohol ingestion). Isopropyl alcohol laboratory findings include the presence of a high serum osmolal gap, presence of ketone bodies in the blood and/or urine (because of acetone), and typically the absence of a high anion gap metabolic acidosis. A brief overview of the in vivo metabolism of methanol and ethylene glycol is presented in Figure 1 and an overview of isopropyl alcohol metabolism is presented in Figure 2.
The management of methanol and ethylene glycol poisoning includes supportive care, respiratory support if needed (mechanical ventilation), the use of cofactors to stimulate formation of less toxic metabolites (see Figures 1 and 2), and the use of either an alcohol dehydrogenase inhibitor (fomepizole) or ethanol, which work by displacing the toxic alcohol and preventing it from being metabolized by alcohol dehydrogenase. Ethanol is less desirable and should only be used in cases of fomepizole unavailability. It is important to remember that fomepizole and ethanol have no effect on the metabolism and clearance of toxic metabolites such as formic acid and glycolic acid. Therefore, inhibition of alcohol dehydrogenase will not translate into 
an improved outcome once the parent alcohol has been metabolized.

RRT should be considered in cases of ongoing hemodynamic instability despite appropriate management and especially in the presence of severe metabolic acidosis, acute kidney injury, and target organ damage (retinal toxicity in methanol and acute kidney injury in ethylene glycol toxicity) $[45,47]$. The small size, low VD, and low protein binding for these alcohols make them readily dialyzable, making standard hemodialysis the first-line therapy for extracorporeal elimination except in cases where hemodialysis is not available or in the setting of significant hemodynamic compromise where CRRT would be indicated [8]. Consensus guidelines recommend hemodialysis when the levels of parent alcohols exceed $50 \mathrm{mg} / \mathrm{dL}$, although some patients without evidence of target organ damage, acute kidney injury, and metabolic acidosis may be managed without hemodialysis. Hemodialysis should also be considered in patients with ethylene glycol poisoning that have a persistent hyperosmolar state (despite appropriate management) [49] and levels of glycolic acid above $8 \mathrm{mmol} / \mathrm{L}$ [50]. It is important to mention that, in cases of methanol poisoning, hemodialysis enhances the clearance of methanol (the endogenous clearance of methanol is slow after alcohol dehydrogenase inhibition) [48], but it only marginally increases the clearance of formic acid [9]. Also, hemodialysis may be less costly than therapy with fomepizole; however, it is essential to remember that hemodialysis is associated with more complications and should be limited to patients with clear indications [51]. End goals of hemodialysis in these patients should be normalization of acid base status, resolution of hyperosmolar states, and a decreased blood level of parent toxic alcohols (less than $25 \mathrm{mg} / \mathrm{dL}$ ). Redistribution of methanol and ethylene glycol can occur after hemodialysis and the serum electrolytes, osmolality, and acid base status should be monitored for additional 12-36 hours after the last hemodialysis treatment $[47,48]$.

Literature on the role of hemodialysis in the management of diethylene glycol is scant [45], and it is unclear whether the active toxic metabolite is removed by hemodialysis. Nevertheless, hemodialysis should be considered in patients with progressive clinical deterioration despite appropriate care and persistent high anion gap metabolic acidosis.

In cases of isopropyl alcohol toxicity, the role of hemodialysis is less clear [44]. Isopropyl alcohol intoxication generally has a more favorable outcome compared to methanol and ethylene glycol poisonings and the vast majority of patients will improve with supportive therapy and alcohol dehydrogenase inhibition. In the rare patient with hemodynamic instability and an isopropyl alcohol level above $4,000 \mathrm{mg} / \mathrm{dL}$ (which is usually due to a massive ingestion), hemodialysis may be considered.

When considering renal replacement therapy in these patients, it is important to note that both fomepizole and ethanol are cleared by hemodialysis and the doses of fomepizole and ethanol should be adjusted accordingly.

An overview of the clinical presentations, major laboratory findings, general principles of management, and indications for hemodialysis among patients with toxic alcohol ingestion is presented in Table 2. A summary of toxic alcohol pharmacokinetics and the utility of hemodialysis is presented in Table 3.

4.2. Salicylate Toxicity. Salicylates are a group of pharmacologic agents which includes aspirin, bismuth salicylate, and local skin preparations such as salicylic acid and methyl salicylate (topical preparations occasionally cause toxicity if used excessively or in patients with skin damage leading to increased absorption) $[10,52,53]$.

Analgesics including aspirin are the most common etiology of all drug poisonings in the USA, and salicylate poisoning caused 34 out of 2,113 deaths due to poisonings reported in 2013 [51]. The major mechanism of action of aspirin is via inhibition of cyclooxygenase enzyme resulting in decreased production of thromboxane A2 and various prostaglandins [11]. However, with higher dosages, other biochemical alterations may occur such as uncoupling of oxidative phosphorylation in the electron transport chain resulting in heat release and stimulation of the respiratory center in the medulla. A decrease in blood $\mathrm{pH}$ will favor formation of lipid-soluble salicylic acid which easily penetrates the blood brain barrier and undergoes renal reabsorption [54]. When used therapeutically, aspirin has a high degree of protein binding which significantly decreases in cases of overdose and poisoning.

Patients with salicylate toxicity typically present with tinnitus, gastrointestinal complications (nausea, vomiting, bleeding, and liver toxicity), hyperthermia (via uncoupling of oxidative phosphorylation), pulmonary edema, and a mixed acid-base disorder (high anion gap metabolic acidosis and respiratory alkalosis via stimulation of respiratory center in the brainstem) [54, 55].

Recent consensus panel guidelines on the management of severe salicylate toxicity recommend intermittent hemodialysis over other modalities of extracorporeal removal [12]. Hemodialysis should be strongly considered in patients with an altered mental status (which may be reflective of high salicylate content in the CNS), pulmonary edema, hypoxemia, fluid overload states or presence of a medical condition limiting the administration of sodium bicarbonate (such as congestive heart failure), presence of either acute or chronic kidney failure (since it will limit the amount of sodium bicarbonate administration and endogenous salicylate clearance), salicylate levels $>90 \mathrm{mg} / \mathrm{dL}$ in acute toxicity and normal renal function and levels $>80 \mathrm{mg} / \mathrm{dL}$ in acute toxicity, and impaired renal function and in cases of failure of appropriate management [12]. A summary of aspirin pharmacokinetics and the utility of hemodialysis is presented in Table 3.

4.3. Lithium Toxicity. Lithium has been used in the management of bipolar disorder since the nineteenth century [56]. The exact mechanism of action of lithium is not clear, but it may involve modulation of intracellular signaling pathways [57]. The major route of lithium elimination is renal excretion, but it is important to note that about $80 \%$ of filtered lithium is reabsorbed [13]. 
TABLE 2: The features of toxic alcohol poisonings.

\begin{tabular}{|c|c|c|c|c|}
\hline $\begin{array}{l}\text { Type of toxic } \\
\text { alcohol }\end{array}$ & $\begin{array}{l}\text { Core clinical } \\
\text { features }\end{array}$ & $\begin{array}{l}\text { Core laboratory } \\
\text { features }\end{array}$ & $\begin{array}{l}\text { General principles of } \\
\text { treatment }\end{array}$ & Indications for RRT \\
\hline Methanol & $\begin{array}{l}\text { CNS depression } \\
\text { AMS } \\
\text { Seizures } \\
\text { Visual } \\
\text { changes/retinal } \\
\text { toxicity } \\
\text { Hemodynamic } \\
\text { instability }\end{array}$ & $\begin{array}{l}\text { HAGMA } \\
\text { High osmolal gap } \\
\text { Elevated lactic acid } \\
\text { (formic acid mediated } \\
\text { inhibition of } \\
\text { mitochondrial } \\
\text { electron transport } \\
\text { chain) }\end{array}$ & $\begin{array}{l}\text { Supportive care } \\
\text { Fomepizole } \\
\text { Ethanol (if fomepizole } \\
\text { is unavailable) } \\
\text { Folic acid or folinic } \\
\text { acid }\end{array}$ & $\begin{array}{l}\mathrm{pH}<7.3 \\
\text { Methanol level }>50 \mathrm{mg} / \mathrm{dL} \\
\text { Visual changes } \\
\text { AKI } \\
\text { Severe electrolyte } \\
\text { derangements } \\
\text { Hemodynamic instability } \\
\text { and progression despite } \\
\text { appropriate care }\end{array}$ \\
\hline Ethylene glycol & $\begin{array}{l}\text { CNS depression } \\
\text { AMS } \\
\text { Seizures } \\
\text { AKI } \\
\text { Calcium oxaluria }\end{array}$ & $\begin{array}{l}\text { HAGMA } \\
\text { High osmolal gap } \\
\text { Hypocalcemia } \\
\text { Electrolyte } \\
\text { abnormalities } \\
\text { AKI } \\
\text { Calcium oxalate } \\
\text { crystals in the urine } \\
\text { Falsely elevated lactic } \\
\text { acid (glycolic acid can } \\
\text { be mistaken for lactic } \\
\text { acid) }\end{array}$ & $\begin{array}{l}\text { Supportive care } \\
\text { Fomepizole } \\
\text { Ethanol (if fomepizole } \\
\text { is unavailable) } \\
\text { Thiamine } \\
\text { Pyridoxine }\end{array}$ & $\begin{array}{l}\mathrm{pH}<7.3 \\
\text { Ethylene glycol level }> \\
50 \mathrm{mg} / \mathrm{dL} \\
\text { Glycolic acid level }> \\
8 \mathrm{mmol} / \mathrm{L} \\
\text { Refractory hyperosmolarity } \\
\text { AKI } \\
\text { Severe electrolyte } \\
\text { derangements } \\
\text { Hemodynamic instability } \\
\text { and progression despite } \\
\text { appropriate care }\end{array}$ \\
\hline $\begin{array}{l}\text { Diethylene } \\
\text { glycol }\end{array}$ & $\begin{array}{l}\text { CNS depression } \\
\text { AMS } \\
\text { Seizures } \\
\text { AKI } \\
\text { Gastrointestinal } \\
\text { symptoms } \\
\text { Peripheral } \\
\text { neuropathy }\end{array}$ & $\begin{array}{l}\text { HAGMA } \\
\text { High osmolal gap } \\
\text { Elevated liver } \\
\text { enzymes }\end{array}$ & $\begin{array}{l}\text { Supportive care } \\
\text { Fomepizole } \\
\text { Ethanol (if fomepizole } \\
\text { is unavailable) } \\
\text { Thiamine } \\
\text { Pyridoxine }\end{array}$ & $\begin{array}{l}\text { Hemodynamic instability } \\
\text { and progression despite } \\
\text { appropriate care } \\
\text { Persistent HAGMA }\end{array}$ \\
\hline $\begin{array}{l}\text { Isopropyl } \\
\text { alcohol }\end{array}$ & $\begin{array}{l}\text { CNS depression } \\
\text { AMS } \\
\text { Hemodynamic } \\
\text { instability in } \\
\text { advanced cases }\end{array}$ & $\begin{array}{l}\text { High osmolal gap } \\
\text { Increased ketones in } \\
\text { the blood and urine } \\
\text { Absence of HAGMA } \\
\text { Falsely elevated } \\
\text { creatinine (due to } \\
\text { acetone cross } \\
\text { reactivity) }\end{array}$ & $\begin{array}{l}\text { Supportive care } \\
\text { Fomepizole } \\
\text { Ethanol (if fomepizole } \\
\text { is unavailable) }\end{array}$ & $\begin{array}{l}\text { Hemodynamic instability } \\
\text { and progression despite } \\
\text { appropriate care } \\
\text { Isopropyl alcohol level > } \\
4000 \mathrm{mg} / \mathrm{dL}\end{array}$ \\
\hline
\end{tabular}

CNS: central nervous system.

AMS: altered mental status.

HAGMA: high anion gap metabolic acidosis.

AKI: acute kidney injury.

Lithium has a narrow therapeutic window and is associated with numerous side effects [57]. Several clinical scenarios of lithium toxicity can occur such as acute overdose in a suicidal patient, acute on chronic toxicity in patients taking lithium whose renal function has declined (e.g., patients with gastroenteritis, decreased oral intake, and patients concomitantly taking other medications such as nonsteroidal anti-inflammatory drugs and angiotensin converting enzyme inhibitors), and chronic toxicity in patients who slowly accumulate the medication and develop toxicity $[14,57]$. Lithium was responsible for 6,610 cases of toxicities including 5 fatalities in the year 2013 [1].

Patients with chronic lithium poisoning typically develop nephrogenic diabetes insipidus and urinary concentrating defects, neurologic symptoms (ataxia, tremors, and altered mental status), hyperparathyroidism, hypothyroidism, and weight gain [14]. Patients with more acute presentations tend to have more pronounced gastrointestinal symptoms such as nausea, vomiting, diarrhea, cardiac arrhythmias, and neurologic symptoms.

Laboratory findings of acute lithium intoxication may include a negative anion gap and an osmolal gap [15]. Also it is important to assess kidney function since acute kidney insults often precipitate lithium toxicity.

The management of lithium intoxication includes stopping the offending medication, supportive care, and, in selected cases, renal replacement therapy such as hemodialysis [15]. Hemodialysis should be considered in patients with lithium levels $>4 \mathrm{mEq} / \mathrm{L}$ regardless of symptomatology and in patients with lithium levels $>2.5 \mathrm{mEq} / \mathrm{L}$ who either 
TABLE 3: Summary of pharmacological and clearance properties of some pharmacological substances* .

\begin{tabular}{|c|c|c|c|c|c|c|}
\hline Substance & $\begin{array}{c}\text { Molecular } \\
\text { weight (daltons) }\end{array}$ & $\begin{array}{c}\text { Protein binding } \\
(\%)\end{array}$ & $\begin{array}{c}\text { Volume of } \\
\text { distribution } \\
(\mathrm{L} / \mathrm{kg})\end{array}$ & $\begin{array}{l}\text { Metabolism and } \\
\text { excretion (\%) }\end{array}$ & $\begin{array}{c}\text { Clearance without } \\
\text { hemodialysis } \\
(\mathrm{mL} / \mathrm{min})\end{array}$ & $\begin{array}{c}\text { Clearance with } \\
\text { hemodialysis } \\
(\mathrm{mL} / \mathrm{min})\end{array}$ \\
\hline Methanol & $\sim 32$ & Minimal & $\sim 0.6-0.77$ & $\begin{array}{c}\sim 95 \text { hepatic } \\
\sim 2.5 \text { respiratory } \\
\sim 1 \text { renal }\end{array}$ & $\sim 11.3$ & $\sim 125-215$ \\
\hline Ethylene glycol & $\sim 62$ & Minimal & $0.5-0.8$ & $\begin{array}{c}\sim 80 \text { hepatic } \\
\sim 20 \text { renal }\end{array}$ & Up to 27 & $145-230$ \\
\hline Diethylene glycol & $\sim 62$ & Minimal & $\sim 1$ & $\begin{array}{c}30-50 \text { hepatic } \\
50-70 \text { renal }\end{array}$ & Unknown & Unknown \\
\hline Isopropyl alcohol & $\sim 60$ & Minimal & $\sim 0.45-0.55$ & $\begin{array}{l}80 \text { hepatic } \\
20 \text { renal }\end{array}$ & Unknown & $\begin{array}{l}137 \text { (isopropyl } \\
\text { alcohol) } \\
\sim 165 \text { (acetone) }\end{array}$ \\
\hline Aspirin & $\sim 180$ & $\begin{array}{l}\sim 49 \\
(\sim 90 \text { with } \\
\text { therapeutic use } \\
\text { and } \sim 30 \text { in } \\
\text { overdose })\end{array}$ & $\sim 0.15$ & $\begin{array}{l}\sim 80 \text { hepatic } \\
\sim 20 \text { renal }\end{array}$ & $0.6-25$ & $3-100$ \\
\hline Lithium & $\sim 74$ & 0 & $\sim 0.3-1$ & $>95$ renal & $20-40$ & $70-170$ \\
\hline Valproic acid & $\sim 144$ & $\begin{array}{l}\text { } 80-90 \\
\text { (continuously } \\
\text { decreases with } \\
\text { higher valproic } \\
\text { acid } \\
\text { concentrations) }\end{array}$ & $\sim 0.1-0.5$ & $\begin{array}{l}\text { Predominantly } \\
\text { hepatic }\end{array}$ & $5-10$ & $\sim 50-90$ \\
\hline Metformin & $\sim 129$ & Minimal & $\sim 1.1$ & $>90$ renal & $\sim 7$ & Up to 170 \\
\hline Dabigatran & 471 & $\sim 35$ & $\sim 0.85$ & $>80$ renal & $\begin{array}{l}\text { Dependent on renal } \\
\text { function }\end{array}$ & $\begin{array}{c}\text { Decreases dabigatran } \\
\text { concentration by at } \\
\text { least } 40 \%\end{array}$ \\
\hline
\end{tabular}

* Adapted from [5-20].

are symptomatic or have some clinical factors (advanced kidney disease and decompensated congestive heart failure) limiting the use of intravenous hydration. The end points of hemodialysis in patients with lithium toxicity are resolution of clinical symptoms of toxicity and lithium levels $<1 \mathrm{mEq} / \mathrm{L}$ [15]. However, it is important to monitor lithium levels after the cessation of hemodialysis, since lithium tissue stores can be redistributed into the bloodstream $[15,16]$. Most cases of lithium intoxication treated with hemodialysis require at least a second session of hemodialysis following rebound. This rebound can be avoided by use of CRRT as described above preferably after the initial hemodialysis session for rapid reduction of lithium level $[8,15]$.

A summary of lithium pharmacokinetics and the utility of hemodialysis is presented in Table 3.

4.4. Valproic Acid Poisoning. Valproic acid is used for the management of epilepsy, bipolar disorder, migraine headaches, and peripheral neuropathy. The mechanism of action includes modulation of gamma aminobutyric acid activity and sodium channel blockade [17]. Valproic acid is a fatty acid and its toxicity is believed to involve the inhibition of mitochondrial beta oxidation [18]. Valproic acid has a favorable molecular weight and volume of distribution to be cleared by hemodialysis, though the degree of protein binding is high at therapeutic concentrations. However, the degree of protein binding decreases with extra therapeutic concentrations due to protein saturation, thus making it amenable for hemodialysis [19]. Valproic acid was responsible for 7,776 toxicities including 2 fatalities in the year 2013 [1].

Clinical manifestations may include altered mental status, tremors, myoclonus, hypotension, tachycardia, and respiratory depression [58]. Classic laboratory abnormalities include hyperammonemia, presence of an osmolal gap, hypernatremia, high anion gap metabolic acidosis, and elevated liver enzymes.

Management of acute valproic acid intoxication includes supportive care, administration of naloxone to help against respiratory depression, and antidote therapy with carnitine supplementation to offset the inhibitory effects on mitochondrial fatty acid oxidation. RRT should be strongly considered in patients with severe toxicity including those with cerebral edema (patients with papilledema, focal neurologic deficits, altered mental status, imaging findings, etc.) and hemodynamic instability and in those with valproic acid levels $>1300 \mathrm{mg} / \mathrm{L}$. RRT should also be considered in patients with valproic acid levels $>900 \mathrm{mg} / \mathrm{L}$, respiratory depression, hyperammonemia, and severe metabolic acidosis $(\mathrm{pH}<7.1)$. Intermittent $\mathrm{HD}$ is the preferred modality of RRT in valproic 
acid poisoning. If hemodialysis is not available, then intermittent hemoperfusion or continuous renal replacement therapy is an acceptable alternative. The end point of hemodialysis includes clinical stabilization and valproic acid levels < $100 \mathrm{mg} / \mathrm{L}$ [19]. As in many other cases of intoxication, it is important to monitor valproic acid levels after the cessation of hemodialysis, since redistribution of the medication can cause reemergence of toxicity. A summary of valproic acid pharmacokinetics and the utility of hemodialysis is presented in Table 3.

4.5. Metformin Poisoning. Metformin is the most commonly used oral antihyperglycemic agent worldwide [58]. Besides treatment of type 2 diabetes mellitus and prediabetes, it is often used in the management of polycystic ovarian syndrome [59]. Metformin's mechanism of action includes decreased hepatic and intestinal gluconeogenesis, enhanced glucose utilization, and modulation of mitochondrial oxidation of fatty acids $[20,59]$. The majority of overdose cases occur in patients with renal disease (either acute or chronic), advanced liver disease, and acute concurrent illness [20]. Metformin was responsible for 8,829 toxicities including 12 fatalities in the year 2013 [1].

The pharmacokinetics of metformin are generally favorable for hemodialysis and extracorporeal elimination such as a low molecular weight and minimal protein binding except with high volume of distribution [20, 21]. Clinical manifestations of metformin poisoning are nonspecific and may include gastrointestinal symptoms such as nausea, vomiting, diarrhea, abdominal pain, altered mental status, and hemodynamic instability. Laboratory features of metformin poisoning include a high anion gap metabolic acidosis due to accumulation of lactic acid. The initial mechanism of lactic acidosis involves modulation of gluconeogenesis [20]. However, later, hemodynamic deterioration may underlie the perpetuation of lactic acidosis.

Treatment of metformin poisoning includes supportive care and RRT. The low molecular weight, negligible plasma protein binding, and rapid transport of drug from cells to serum allow for drug removal by hemodialysis despite a relatively large VD. It is unclear whether hemodialysis improves mortality in patients with metformin poisoning. Furthermore, its efficacy may be suboptimal in patients who present after tissue redistribution occurs as that leads to a large volume of distribution. Nevertheless, hemodialysis should be strongly considered in patients with advanced renal failure, decompensated congestive heart failure, severe metabolic acidosis $(\mathrm{pH}<7.1)$, and hemodynamic and clinical decline despite supportive care [20]. Whenever possible, prolonged sessions of hemodialysis should be undertaken; alternatively CRRT can be considered [22]. A summary of metformin pharmacokinetics and the utility of hemodialysis is presented in Table 3.

4.6. Dabigatran Poisoning. Dabigatran is a non-vitamin K oral anticoagulant used in the management of nonvalvular atrial fibrillation, venous thromboembolism, and postprocedural deep venous thrombosis prophylaxis [23]. Dabigatran represents an alternative to vitamin $\mathrm{K}$ antagonists in the vast majority of patients with the above-mentioned conditions. Dabigatran is predominantly excreted by the kidneys and is contraindicated in patients with advanced renal disease typically defined as creatinine clearance $<30 \mathrm{~mL} / \mathrm{min}$.

The major adverse effect related to the use of dabigatran is bleeding which may be minor or life-threating, such as in case of intracranial hemorrhage. Until recently, the management of bleeding in patients taking dabigatran was supportive [24]. However, recently, a monoclonal antibody, idarucizumab, has been shown to be effective in the management of patients with dabigatran related bleeding [25].

Before the availability of idarucizumab, RRT was used in the bleeding patient taking dabigatran. Several case reports highlighted the efficacy of RRT in the management of patients with dabigatran related bleeding [26]. In a small study, intermittent hemodialysis enhanced elimination of dabigatran more efficiently than CRRT, though dabigatran levels may rebound after cessation of hemodialysis via the effect of redistribution [27]. Dabigatran levels should be repeated and repeat hemodialysis should be considered in patients with a rebound increase in dabigatran concentration. Alternatively, longer duration hemodialysis sessions or CRRT may be considered specifically that most patients with dabigatran toxicity are critically ill with life-threatening bleeding or are in need for an emergent surgery, where CRRT would be more tolerated. However, it is important that the vast majority of patients with dabigatran poisoning do not have advanced renal disease and do not receive renal replacement therapy. Therefore, a dialysis vascular catheter must be inserted which may be difficult in an overanticoagulated patient and result in more bleeding and other complications. Thus, RRT should be considered in patients with severe bleeding and patients on dabigatran requiring emergent surgery when idarucizumab is not available. It is important to note that RRT does not have a role in the management of other non-vitamin $\mathrm{K}$ anticoagulants.

A summary of dabigatran pharmacokinetics and the utility of hemodialysis is presented in Table 3.

4.7. Miscellaneous Pharmacologic Poisonings. RRT has been effective in the management of various medication related toxicities [28-41, 60-66]. It is important to note that scientific data is limited to case reports and case series. RRT should be considered in patients with severe toxicity after failure of supportive care. A summary of some of these medications and the role of hemodialysis in the management of these toxicities is presented in Table 4.

\section{Conclusion}

The use of RRT should be considered in patients with toxic alcohol poisoning, salicylate toxicity, lithium overdose, and metformin poisoning as well as valproic acid toxicity. The role of RRT in the management of dabigatran toxicity is likely limited to cases with severe bleeding when idarucizumab is not available. RRT use should also be considered in the management of other drug toxicities on a case-by-case basis. 
TABLE 4: Role of hemodialysis in the management of miscellaneous pharmacological poisonings.

\begin{tabular}{|c|c|c|c|c|}
\hline Medication & Therapeutic use & Classic toxicity & Treatment & Efficacy of hemodialysis (HD) \\
\hline Carbamazepine & $\begin{array}{c}\text { Epilepsy } \\
\text { Trigeminal neuralgia } \\
\text { Bipolar disorder }\end{array}$ & $\begin{array}{l}\text { Altered mental status } \\
\text { Seizures } \\
\text { Hemodynamic } \\
\text { instability } \\
\text { Arrhythmias }\end{array}$ & Supportive & $\begin{array}{l}\text { May reduce carbamazepine level } \\
\text { by about } 50 \%[21-23]\end{array}$ \\
\hline Phenobarbital & Epilepsy & Altered mental status & Supportive & $\begin{array}{l}\text { May reduce phenobarbital level } \\
\text { by up to } 59 \% \text { after } 4 \text { h HD } \\
\text { [24-26] }\end{array}$ \\
\hline Phenytoin & $\begin{array}{c}\text { Epilepsy } \\
\text { Cardiac arrhythmias }\end{array}$ & $\begin{array}{l}\text { Horizontal nystagmus } \\
\text { Ataxia } \\
\text { Altered mental status } \\
\text { Arrhythmias } \\
\text { Hypersensitivity } \\
\text { reactions }\end{array}$ & Supportive & $\begin{array}{l}\text { Should be considered in patients } \\
\text { with severe poisoning not } \\
\text { responding to supportive care } \\
\text { [27] }\end{array}$ \\
\hline Baclofen & Spasticity & $\begin{array}{l}\text { Muscle hypotonia } \\
\text { Altered mental status } \\
\text { Hemodynamic } \\
\text { instability }\end{array}$ & Supportive & $\begin{array}{l}\text { Conventional HD can decrease } \\
\text { the concentration by up to } 79 \% \\
{[28-30]}\end{array}$ \\
\hline Eptifibatide & $\begin{array}{l}\text { Antiplatelet agent } \\
\text { Acute coronary } \\
\text { syndrome }\end{array}$ & Bleeding & $\begin{array}{l}\text { Supportive } \\
\text { Platelet } \\
\text { transfusion }\end{array}$ & $\begin{array}{l}\text { Limited to patients with renal } \\
\text { failure experiencing ongoing } \\
\text { severe bleeding not responding } \\
\text { to supportive care [31] }\end{array}$ \\
\hline $\begin{array}{l}\text { Diltiazem } \\
\text { Atenolol }\end{array}$ & $\begin{array}{l}\text { Hypertension } \\
\text { Cardiac arrhythmias }\end{array}$ & $\begin{array}{l}\text { Bradycardia } \\
\text { Hemodynamic } \\
\text { instability }\end{array}$ & Supportive & $\begin{array}{l}\text { HD may be considered in } \\
\text { unstable patient with renal } \\
\text { failure not responding to } \\
\text { supportive care }[32,33]\end{array}$ \\
\hline Lisinopril & $\begin{array}{l}\text { Hypertension } \\
\text { Heart failure } \\
\text { Renal disease }\end{array}$ & $\begin{array}{l}\text { Acute kidney injury } \\
\text { Hyperkalemia } \\
\text { Hemodynamic } \\
\text { instability } \\
\text { Angioedema }\end{array}$ & Supportive & $\begin{array}{l}\text { HD may be considered in } \\
\text { unstable patient with renal } \\
\text { failure not responding to } \\
\text { supportive care [34] }\end{array}$ \\
\hline Theophylline & $\begin{array}{l}\text { Obstructive pulmonary } \\
\text { disease }\end{array}$ & $\begin{array}{l}\text { Arrhythmias } \\
\text { Altered mental status } \\
\text { Seizures }\end{array}$ & Supportive & $\begin{array}{l}\text { HD may be considered in } \\
\text { unstable patient with renal } \\
\text { failure not responding to } \\
\text { supportive care }[35,36]\end{array}$ \\
\hline Cefepime & Antibiotic & $\begin{array}{l}\text { Neurotoxicity } \\
\text { Altered mental status }\end{array}$ & Supportive & $\begin{array}{l}\text { HD may be considered in } \\
\text { unstable patient with renal } \\
\text { failure not responding to } \\
\text { supportive care [37] }\end{array}$ \\
\hline Metronidazole & Antibiotic & $\begin{array}{l}\text { Altered mental status } \\
\text { Seizures } \\
\text { Neuropathy } \\
\text { Gastrointestinal } \\
\text { symptoms }\end{array}$ & Supportive & $\begin{array}{l}\text { HD should be considered in } \\
\text { patient with metronidazole } \\
\text { overdose and renal failure [38] }\end{array}$ \\
\hline Dapsone & Antibiotic & $\begin{array}{l}\text { Hypersensitivity } \\
\text { reactions } \\
\text { Methemoglobinemia }\end{array}$ & $\begin{array}{l}\text { Supportive } \\
\text { Methylene blue }\end{array}$ & $\begin{array}{l}\text { HD should be considered in } \\
\text { patients not responding to } \\
\text { conventional therapy [39] }\end{array}$ \\
\hline Isoniazid & Antibiotic & $\begin{array}{l}\text { Neurotoxicity } \\
\text { Seizures } \\
\text { Liver toxicity }\end{array}$ & $\begin{array}{l}\text { Supportive } \\
\text { Pyridoxine }\end{array}$ & $\begin{array}{l}\text { HD should be considered in } \\
\text { patients not responding to } \\
\text { conventional therapy [40] }\end{array}$ \\
\hline Acetaminophen & Analgesic & Liver failure & $\begin{array}{c}\text { Supportive } \\
\mathrm{N} \text { - } \\
\text { Acetylcysteine } \\
\text { Liver transplant }\end{array}$ & $\begin{array}{l}\text { HD may be considered in } \\
\text { unstable patients with metabolic } \\
\text { acidosis [41] }\end{array}$ \\
\hline
\end{tabular}




\section{Additional Points}

Why is this topic important? It critically reviews the scientific literature on the management of pharmacological toxidromes. What does this review attempt to show? It attempts to show the role of hemodialysis in the management of pharmacological poisonings. What are the key findings? Hemodialysis should be strongly considered in patients with toxic alcohol ingestion, salicylate overdose, severe valproic acid toxicity, metformin overdose, and lithium poisoning. Hemodialysis should be considered on case-by-case basis in the management of toxidromes secondary to other pharmacological agents. How is patient care impacted? Hemodialysis in the management of various pharmacological toxidromes which can be fatal should be considered. Early consultation with nephrologist regarding hemodialysis initiation is advised.

\section{Competing Interests}

The authors declare that there are no competing interests regarding the publication of this paper.

\section{References}

[1] J. B. Mowry, D. A. Spyker, L. R. Cantilena Jr., N. McMillan, and M. Ford, "2013 annual report of the American Association of Poison Control Centers' National Poison Data System (NPDS): 31st annual report," Clinical Toxicology, vol. 52, no. 10, pp. 10321283, 2014.

[2] S. H. Rhyee, L. Farrugia, S. L. Campleman, P. M. Wax, and J. Brent, "The toxicology investigators consortium case registrythe 2014 experience," Journal of Medical Toxicology, vol. 11, no. 4, pp. 388-409, 2015.

[3] J. M. Orlowski, S. Hou, and J. B. Leikin, "Extracorporeal removal of drugs and toxins," Clinical Toxicology, 1st Edition, pp. 43-50, 2001.

[4] D. Goldfarb, "Principles and techniques applied to enhance elimination," in Goldfrank's Toxicologic Emergencies, L. Nelson, N. A. Lewin, M. A. Howland, R. S. Hoffman, L. R. Goldfrank, and N. E. Flomenbaum, Eds., pp. 135-148, McGraw-Hill, 9th edition, 2010.

[5] N. S. Kanagasundaram and A. Lewington, "Dialytic therapies for drug overdose and poisoning," in Comprehensive Clinical Nephrology, chapter 98, pp. 1116-1121, 5th edition, 2014.

[6] G. Villa, Z. Ricci, and C. Ronco, "Renal Replacement Therapy," Critical Care Clinics, vol. 31, no. 4, pp. 839-848, 2015.

[7] L. G. Forni and P. J. Hilton, "Continuous hemofiltration in the treatment of acute renal failure," New England Journal of Medicine, vol. 336, no. 18, pp. 1303-1309, 1997.

[8] Z. Kim and D. S. Goldfarb, "Continuous renal replacement therapy does not have a clear role in the treatment of poisoning," Nephron-Clinical Practice, vol. 115, pp. cl-c6, 2010.

[9] W. Kerns II, C. Tomaszewski, K. McMartin et al., "Formate kinetics in methanol poisoning," Journal of Toxicology-Clinical Toxicology, vol. 40, no. 2, pp. 137-143, 2002.

[10] J. E. Davis, "Are one or two dangerous? Methyl salicylate exposure in toddlers," Journal of Emergency Medicine, vol. 32, no. 1, pp. 63-69, 2007.

[11] J. Y. Wick, "Aspirin: a history, a love story," Consultant Pharmacist, vol. 27, no. 5, pp. 322-329, 2012.
[12] D. N. Juurlink, S. Gosselin, J. T. Kielstein et al., "Extracorporeal treatment for salicylate poisoning: systematic review and recommendations from the EXTRIP workgroup," Annals of Emergency Medicine, vol. 66, no. 2, pp. 165-181, 2015.

[13] M. E. Ward, M. N. Musa, and L. Bailey, "Clinical pharmacokinetics of lithium," Journal of Clinical Pharmacology, vol. 34, no. 4, pp. 280-285, 1994.

[14] R. F. McKnight, M. Adida, K. Budge, S. Stockton, G. M. Goodwin, and J. R. Geddes, "Lithium toxicity profile: a systematic review and meta-analysis," The Lancet, vol. 379, no. 9817, pp. 721728, 2012.

[15] M. M. Sood and R. Richardson, "Negative anion gap and elevated osmolar gap due to lithium overdose," Canadian Medical Association Journal, vol. 176, no. 7, pp. 921-923, 2007.

[16] F. Eyer, R. Pfab, N. Felgenhauer et al., "Lithium poisoning: pharmacokinetics and clearance during different therapeutic measures," Journal of Clinical Psychopharmacology, vol. 26, no. 3, pp. 325-330, 2006.

[17] R. M. Nanau and M. G. Neuman, "Adverse drug reactions induced by valproic acid," Clinical Biochemistry, vol. 46, no. 15, pp. 1323-1338, 2013.

[18] M. F. B. Silva, C. C. P. Aires, P. B. M. Luis et al., "Valproic acid metabolism and its effects on mitochondrial fatty acid oxidation: a review," Journal of Inherited Metabolic Disease, vol. 31, no. 2, pp. 205-216, 2008.

[19] M. Ghannoum, M. Laliberté, T. D. Nolin et al., "Extracorporeal treatment for valproic acid poisoning: systematic review and recommendations from the EXTRIP workgroup," Clinical Toxicology, vol. 53, no. 5, pp. 454-465, 2015.

[20] K. T. Kopec and M. J. Kowalski, "Metformin-Associated Lactic Acidosis (MALA): case files of the Einstein Medical Center medical toxicology fellowship," Journal of Medical Toxicology, vol. 9, no. 1, pp. 61-66, 2013.

[21] A. J. Scheen, "Clinical pharmacokinetics of metformin," Clinical Pharmacokinetics, vol. 30, no. 5, pp. 359-371, 1996.

[22] S. I. Rifkin, C. McFarren, R. Juvvadi, and S. S. Weinstein, "Prolonged hemodialysis for severe metformin intoxication," Renal Failure, vol. 33, no. 4, pp. 459-461, 2011.

[23] G. J. Hankey and J. W. Eikelboom, "Dabigatran etexilate: a new oral thrombin inhibitor," Circulation, vol. 123, no. 13, pp. 14361450, 2011.

[24] R. Alikhan, R. Rayment, D. Keeling et al., "The acute management of haemorrhage, surgery and overdose in patients receiving dabigatran," Emergency Medicine Journal, vol. 31, no. 2, pp. 163-168, 2014.

[25] C. V. Pollack Jr., P. A. Reilly, J. Eikelboom et al., "Idarucizumab for dabigatran reversal," New England Journal of Medicine, vol. 373, no. 6, pp. 511-520, 2015.

[26] C. Chai-Adisaksopha, C. Hillis, W. Lim, K. Boonyawat, K. Moffat, and M. Crowther, "Hemodialysis for the treatment of dabigatran-associated bleeding: a case report and systematic review," Journal of Thrombosis and Haemostasis, vol. 13, no. 10, pp. 1790-1798, 2015.

[27] J. Bouchard, M. Ghannoum, A. Bernier-Jean et al., "Comparison of intermittent and continuous extracorporeal treatments for the enhanced elimination of dabigatran," Clinical Toxicology, vol. 53, no. 3, pp. 156-163, 2015.

[28] J. L. Harder, M. Heung, A. M. Vilay, B. A. Mueller, and J. H. Segal, "Carbamazepine and the active epoxide metabolite are effectively cleared by hemodialysis followed by continuous venovenous hemodialysis in an acute overdose," Hemodialysis International, vol. 15, no. 3, pp. 412-415, 2011. 
[29] A. Ozhasenekler, S. Gökhan, C. Güloğlu, M. Orak, and M. Ustündağ, "Benefit of hemodialysis in carbamazepine intoxications with neurological complications," European Review for Medical and Pharmacological Sciences, vol. 16, supplement 1, pp. 43-47, 2012.

[30] A. Azak, G. Koçak, B. Huddam, and M. Duranay, "Is conventional hemodialysis enough to manage carbamazepine intoxication?" Blood Purification, vol. 33, no. 4, pp. 225-226, 2012.

[31] B. F. Palmer, "Effectiveness of hemodialysis the extracorporeal therapy of phenobarbital overdose," American Journal of Kidney Diseases, vol. 36, no. 3, pp. 640-643, 2000.

[32] F. Jacobs and F. G. Brivet, "Conventional haemodialysis significantly lowers toxic levels of phenobarbital," Nephrology Dialysis Transplantation, vol. 19, no. 6, pp. 1663-1664, 2004.

[33] K. Hoyland, M. Hoy, R. Austin, and M. Wildman, "Successful use of haemodialysis to treat phenobarbital overdose," BMJ Case Reports, vol. 2013, 2013.

[34] M. Ghannoum, S. Troyanov, P. Ayoub, V. Lavergne, and T. Hewlett, "Successful hemodialysis in a phenytoin overdose: case report and review of the literature," Clinical Nephrology, vol. 74, no. 1, pp. 59-64, 2010.

[35] V.-C. Wu, S.-L. Lin, S.-M. Lin, and C.-C. Fang, "Treatment of baclofen overdose by haemodialysis: A Pharmacokinetic Study," Nephrology Dialysis Transplantation, vol. 20, no. 2, pp. 441-443, 2005.

[36] M. Brvar, M. Vrtovec, D. Kovač, G. Kozelj, T. Pezdir, and M. Bunc, "Haemodialysis clearance of baclofen," European Journal of Clinical Pharmacology, vol. 63, no. 12, pp. 1143-1146, 2007.

[37] M.-J. Hsieh, S.-C. Chen, T.-I. Weng, C.-C. Fang, and T.-J. Tsai, "Treating baclofen overdose by hemodialysis," American Journal of Emergency Medicine, vol. 30, no. 8, pp. 1654.e51654.e7, 2012.

[38] R. T. Sperling, D. S. Pinto, K. K. L. Ho, and J. P. Carrozza Jr., "Platelet glycoprotein IIb/IIIa inhibition with eptifibatide: prolongation of inhibition of aggregation in acute renal failure and reversal with hemodialysis," Catheterization and Cardiovascular Interventions, vol. 59, no. 4, pp. 459-462, 2003.

[39] C. P. Snook, K. Sigvaldason, and J. Kristinsson, "Severe atenolol and diltiazem overdose," Journal of Toxicology-Clinical Toxicology, vol. 38, no. 6, pp. 661-665, 2000.

[40] S.-H. S. Huang, R. G. Tirona, C. Ross, and R. S. Suri, "Case report: atenolol overdose successfully treated with hemodialysis," Hemodialysis International, vol. 17, no. 4, pp. 652-655, 2013.

[41] T. W. Belay and A. R. Nusair, "Apparent lisinopril overdose requiring hemodialysis," American Journal of Health-System Pharmacy, vol. 70, no. 14, pp. 1226-1229, 2013.

[42] A. S. Shalkham, B. M. Kirrane, R. S. Hoffman, D. S. Goldfarb, and L. S. Nelson, "The availability and use of charcoal hemoperfusion in the treatment of poisoned patients," American Journal of Kidney Diseases, vol. 48, no. 2, pp. 239-241, 2006.

[43] J. A. Kraut, "Diagnosis of toxic alcohols: limitations of present methods," Clinical Toxicology, vol. 53, no. 7, pp. 589-595, 2015.

[44] R. J. Slaughter, R. W. Mason, D. M. G. Beasley, J. A. Vale, and L. J. Schep, "Isopropanol poisoning," Clinical Toxicology, vol. 52, no. 5, pp. 470-478, 2014.

[45] L. J. Schep, R. J. Slaughter, W. A. Temple, and D. M. G. Beasley, "Diethylene glycol poisoning," Clinical Toxicology, vol. 47, no. 6, pp. 525-535, 2009.

[46] H. K. Tan, "Molecular adsorbent recirculating system (MARS)," Annals of the Academy of Medicine Singapore, vol. 33, no. 3, pp. 329-335, 2004.
[47] D. G. Barceloux, E. P. Krenzelok, K. Olson, W. Watson, and H. Miller, "American academy of clinical toxicology practice guidelines on the treatment of ethylene glycol poisoning," Journal of Toxicology_Clinical Toxicology, vol. 37, no. 5, p. 537, 1999.

[48] D. G. Barceloux, G. R. Bond, E. P. Krenzelok, H. Cooper, and J. A. Vale, "American Academy of Clinical Toxicology practice guidelines on the treatment of methanol poisoning," Journal of Toxicology-Clinical Toxicology, vol. 40, no. 4, pp. 415-446, 2002.

[49] A. Pizon and D. Brooks, "Hyperosmolality: another indication for hemodialysis following acute ethylene glycol poisoning," Clinical Toxicology, vol. 44, no. 2, pp. 181-183, 2006.

[50] W. H. Porter, P. W. Rutter, B. A. Bush, A. A. Pappas, and J. E. Dunnington, "Ethylene glycol toxicity: the role of serum glycolic acid in hemodialysis," Journal of Toxicology-Clinical Toxicology, vol. 39, no. 6, pp. 607-615, 2001.

[51] M. A. Darracq, L. L. Rentmeester, R. F. Clark, C. A. Tomaszewski, A. B. Schneir, and F. L. Cantrell, "Cost of hemodialysis versus fomepizole-only for treatment of ethylene glycol intoxication," Clinical Toxicology, vol. 51, no. 3, p. 188, 2013.

[52] J. Herres, D. Ryan, and M. Salzman, "Delayed salicylate toxicity with undetectable initial levels after large-dose aspirin ingestion," American Journal of Emergency Medicine, vol. 27, no. 9, pp. 1173-e1, 2009.

[53] A. Wong, K. Mac, A. Aneman, J. Wong, and B. S. Chan, "Modern Intermittent Haemodialysis (IHD) is an effective method of removing salicylate in chronic topical salicylate toxicity," Journal of Medical Toxicology, vol. 12, no. 1, pp. 130-133, 2015.

[54] J. B. Hill, "Salicylate intoxication," New England Journal of Medicine, vol. 288, no. 21, pp. 1110-1113, 1973.

[55] J. K. Glisson, T. S. Vesa, and M. R. Bowling, "Current management of salicylate-induced pulmonary edema," Southern Medical Journal, vol. 104, no. 3, pp. 225-232, 2011.

[56] A. D. Strobusch and J. W. Jefferson, "The checkered history of lithium in medicine," Pharmacy in History, vol. 22, no. 2, pp. 72-76, 1980.

[57] R. Oruch, M. A. Elderbi, H. A. Khattab, I. F. Pryme, and A. Lund, "Lithium: a review of pharmacology, clinical uses, and toxicity," European Journal of Pharmacology, vol. 740, pp. 464-473, 2014.

[58] M. D. Sztajnkrycer, "Valproic acid toxicity: overview and management," Journal of Toxicology-Clinical Toxicology, vol. 40, no. 6, pp. 789-801, 2002.

[59] J. Hajjar, M. A. Habra, and A. Naing, "Metformin: an old drug with new potential," Expert Opinion on Investigational Drugs, vol. 22, no. 12, pp. 1511-1517, 2013.

[60] S. Okada, S. Teramoto, and R. Matsuoka, "Recovery from theophylline toxicity by continuous hemodialysis with filtration," Annals of Internal Medicine, vol. 133, no. 11, p. 922, 2000.

[61] J. Kneser, P. Wehmeier, R. Lichtinghagen, M. M. Hoeper, and J. T. Kielstein, "Successful treatment of life threatening theophylline intoxication in a pregnant patient by hemodialysis," Clinical Nephrology, vol. 80, no. 1, pp. 72-74, 2013.

[62] L.-Y. Mani, S. Kissling, D. Viceic et al., "Intermittent hemodialysis treatment in cefepime-induced neurotoxicity: case report, pharmacokinetic modeling, and review of the literature," Hemodialysis International, vol. 19, no. 2, pp. 333-343, 2015.

[63] A. M. Burda, C. B. Fischbein, T. Howe, T. R. Sigg, and M. A. Wahl, "Hemodialysis clearance of metronidazole following overdose," Annals of Pharmacotherapy, vol. 39, no. 7-8, p. 1366, 2005. 
[64] G. Thunga, K. G. Sam, D. Patel et al., "Effectiveness of hemodialysis in acute dapsone overdose-a case report," American Journal of Emergency Medicine, vol. 26, no. 9, pp. 1070.el1070.e4, 2008.

[65] K. Skinner, A. Saiao, A. Mostafa et al., "Isoniazid poisoning: pharmacokinetics and effect of hemodialysis in a massive ingestion," Hemodialysis International, vol. 19, no. 4, pp. E37E40, 2015.

[66] M. L. A. Sivilotti, D. N. Juurlink, J. S. Garland et al., "Antidote removal during haemodialysis for massive acetaminophen overdose," Clinical Toxicology, vol. 51, no. 9, pp. 855-863, 2013. 


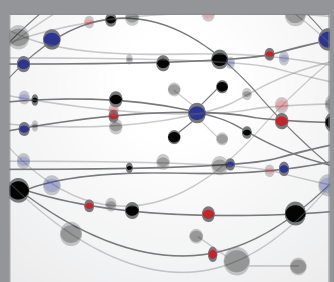

The Scientific World Journal
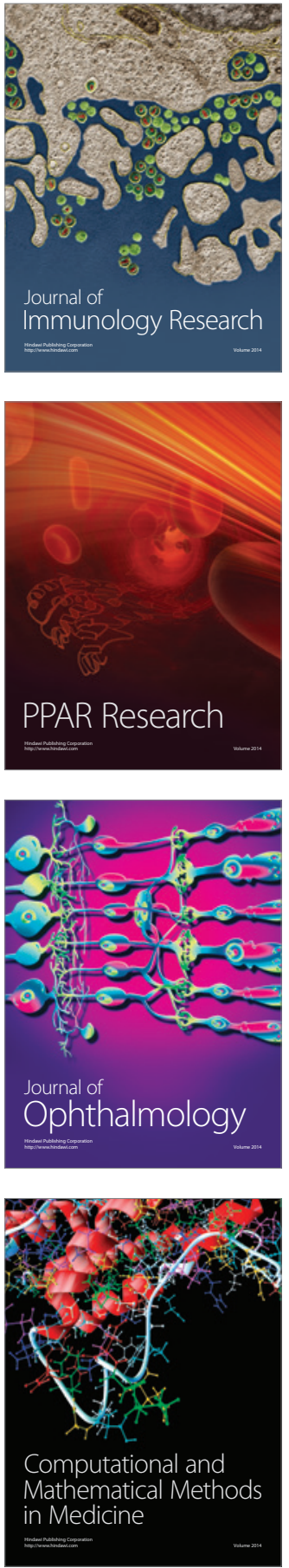

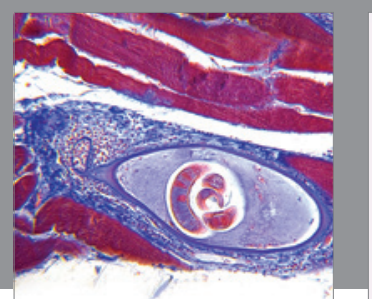

Gastroenterology Research and Practice

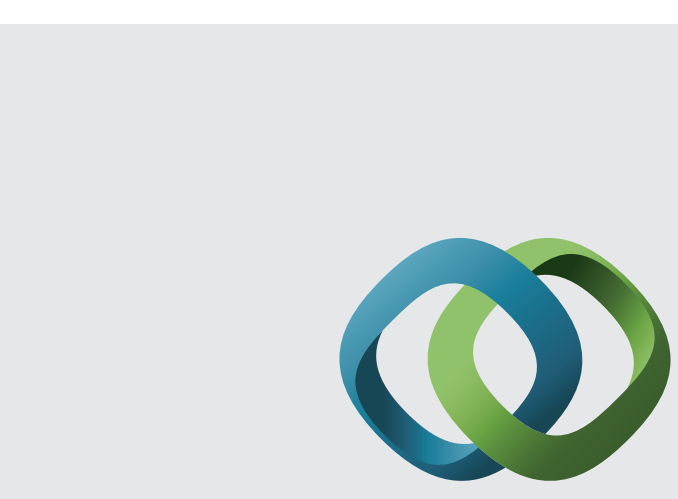

\section{Hindawi}

Submit your manuscripts at

http://www.hindawi.com
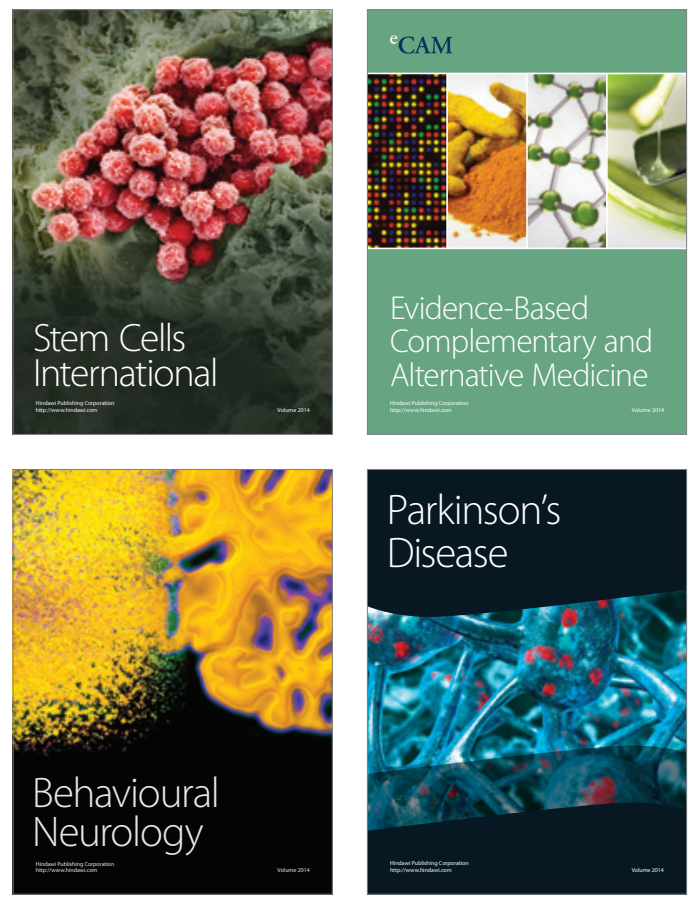
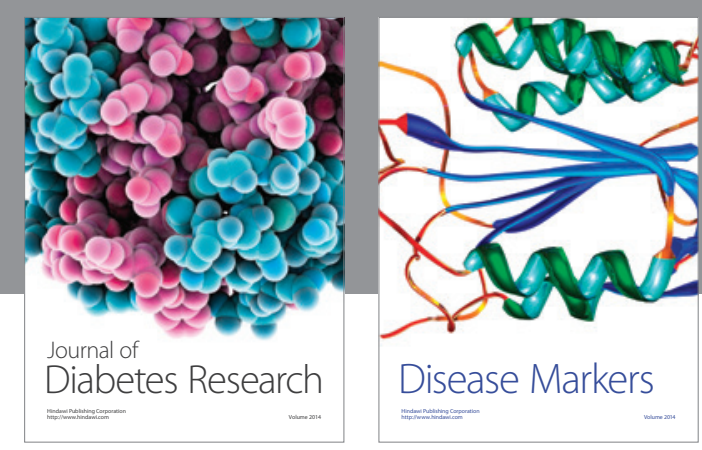

Disease Markers
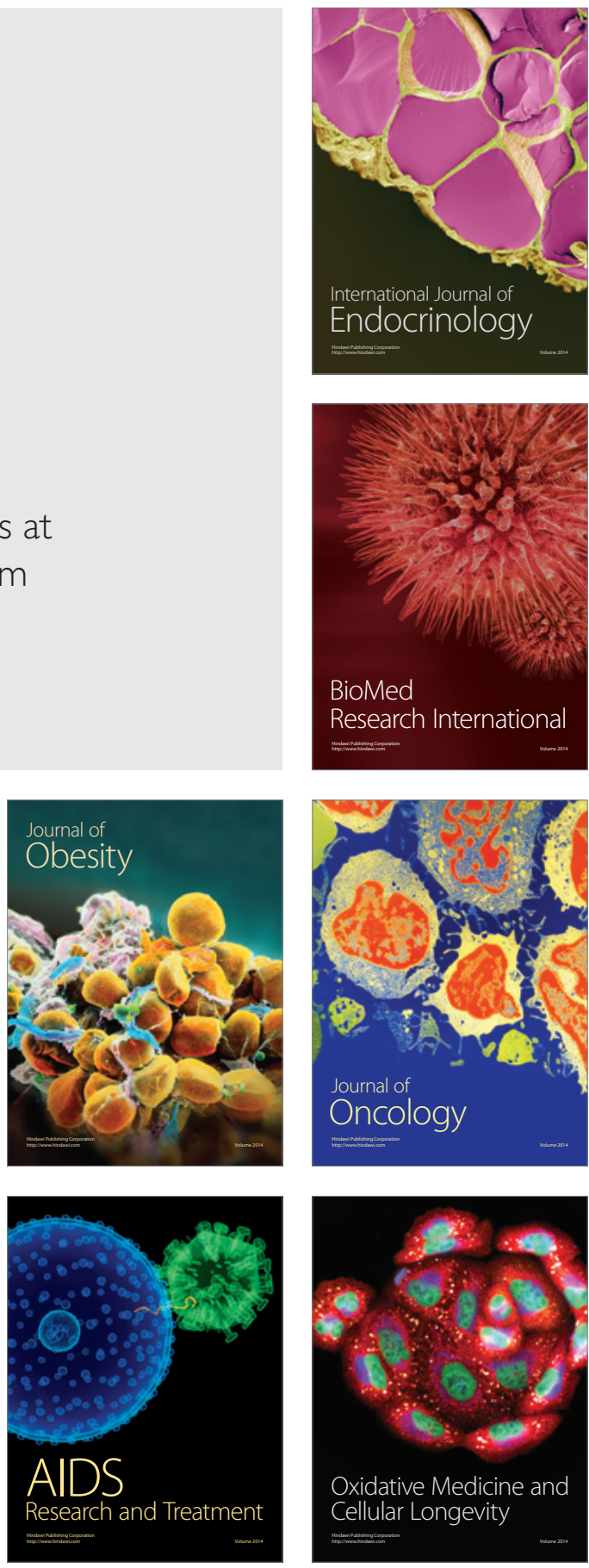